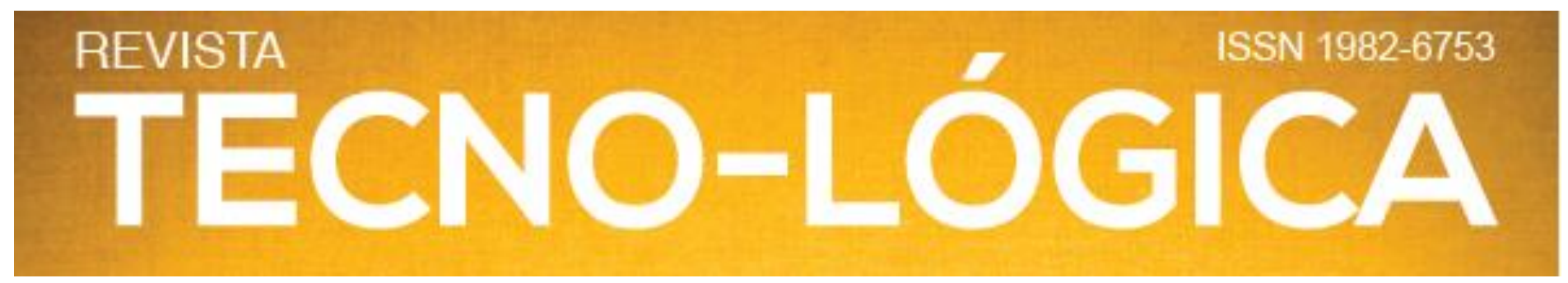

\title{
QUALIDADE DA SEMEADURA DE MILHO NO PLANALTO MÉDIO DO RIO GRANDE DO SUL
}

\author{
Felipe Arthur Baron ${ }^{1}$, Marcelo Silveira de Farias ${ }^{2 *}$, Luís Felipe Rossetto Gerlach ${ }^{2}$, Ezequiel Zibetti Fornari ${ }^{2}$, Antônio Luis Santi ${ }^{2}$ \\ 1 Connect Farm, Cachoeira do Sul,RS - Brasil. \\ 2 Departamento de Ciências Agronômicas e Ambientais, Universidade Federal de Santa Maria, Campus de Frederico Westphalen, \\ 98400-000, Frederico Westphalen, RS - Brasil.
}

*E-mail: silveira_farias@hotmail.com

\section{RESUMO}

O objetivo deste trabalho foi determinar a qualidade na distribuição de plantas de milho na linha de semeadura, na região do Planalto Médio do Estado do Rio Grande do Sul. O estudo foi realizado no ano agrícola 2018/19, em 23 áreas de cultivo de milho, sendo 14 em sistema irrigado e nove no sistema sequeiro, localizadas em 11 municípios gaúchos. Em cada área foi mensurada a distância longitudinal entre plantas de milho na linha de semeadura, em estádio vegetativo V3. Para tanto, foram avaliados 10 metros de plantas, em três repetições, e os dados foram tabulados e distribuídos em: espaçamentos aceitáveis, duplos e falhos. De acordo com classificação proposta na literatura clássica, 56,5\% das áreas avaliadas encontram-se em ótimo estado de distribuição de plantas na linha, 39,1\% em bom estado, e 4,4\% das áreas em estado regular de qualidade da semeadura do milho. Ao observar os dois sistemas de cultivo, as médias de espaçamentos aceitáveis foi de $87,0 \%$ para o sistema irrigado, e de $93,8 \%$ para o sequeiro. Pode-se concluir que, para a maioria das áreas avaliadas, a qualidade da semeadura da cultura do milho na região do Planalto Médio é ótima.

Palavras-chave: Mecanização agrícola. Sistema de Plantio Direto. Plantabilidade.

\section{Introdução}

A competitividade imposta ao setor produtivo brasileiro faz com que o agricultor busque alternativas para aumentar a produtividade sem aumentar os custos de produção [1]. Neste sentido, tem-se dado maior atenção para a qualidade de semeadura para a cultura do milho [2].

A correta distribuição longitudinal das sementes pela semeadora é uma das características que mais contribuem para a obtenção de estande uniforme de plantas, importante para alcançar altos tetos produtivos [3-4]. Ainda, de acordo com Madalóz [5], inúmeros são os fatores que podem contribuir para a qualidade da distribuição de plantas dentre estes, a correta regulagem da semeadora, por meio da escolha adequada dos discos dosadores e pressão de vácuo, uso de grafite e da velocidade de trabalho.

Segundo Hörbe [6], a redução de, aproximadamente, 16 pontos percentuais no coeficiente de variação do espaçamento entre plantas de milho utilizando semeadora com sistema pneumático de distribuição de sementes, ocasionou incremento de 9,65\%, em média, na produtividade, em relação à semeadora com sistema mecânico de distribuição de sementes. Ainda, segundo o autor, em levantamentos de campo, embora haja preocupação com a precisão da distribuição de sementes no processo de semeadura, é constatada baixa qualidade na distribuição de plantas na linha de semeadura.

A irregularidade na distribuição de plantas pode reduzir a eficiência de aproveitamento de água, luz e nutrientes da comunidade, aumentando o número de plantas com desenvolvimento fenológico retardado, colmos frágeis, que se apresentam dominadas na lavoura [3]. Ainda, segundo os autores, a diminuição do erro no espaçamento entre plantas acarreta no incremento na produtividade de milho.

A desuniformidade da distribuição de sementes é caracterizada pela presença de espaçamentos duplos e falhos. O primeiro causa acúmulo de plantas em determinados pontos da linha de semeadura, gerando plantas com maior altura e menor 


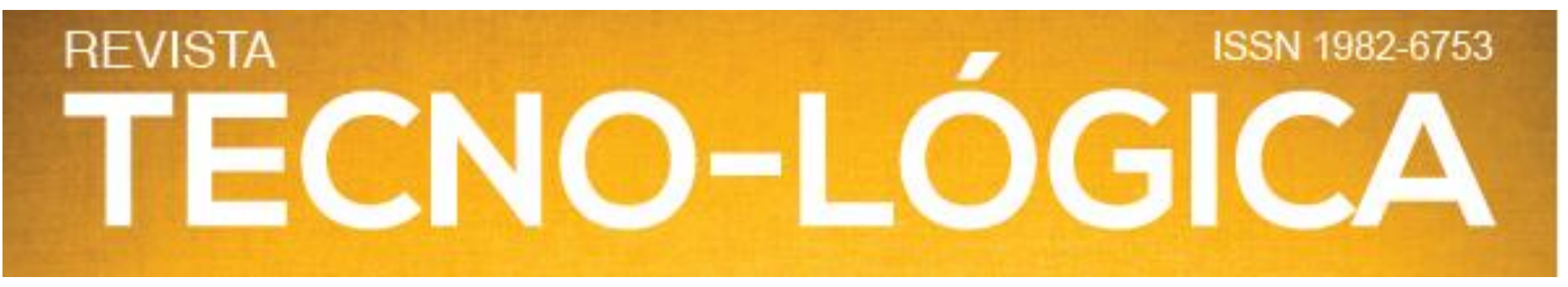

diâmetro de caule, tornando-as susceptíveis ao acamamento. Já, as falhas na distribuição de sementes favorecem o surgimento de plantas daninhas, pela ineficiência de fechamento do dossel da cultura, influenciando a redução de produtividade [7].

Em avaliações de áreas comerciais de produção de milho, na região dos Campos Gerais, no Estado do Paraná, Schimandeiro et al. [8] afirmam que, a população de plantas desejada estava sendo alcançada, porém existia grande variabilidade na distribuição das plantas na linha de semeadura, sugerindo a necessidade de ações de pesquisa e extensão junto aos produtores rurais da região.

Devido à necessidade de se conhecer a real situação da operação agrícola mecanizada de semeadura direta da cultura do milho, este trabalho teve como objetivo determinar a qualidade na distribuição de plantas de milho na linha de semeadura, no Planalto Médio do Estado do Rio Grande do Sul (RS).

\section{Materiais e Métodos}

O estudo foi realizado no ano agrícola 2018/19, em 23 áreas de cultivo de milho, sendo 14 em sistema irrigado e noveno sistema sequeiro, todas incluídas no Projeto Construindo e Desafiando a Produtividade - Connect Farm. As áreas pertencem a 12 produtores rurais e estão localizadas em 11 municípios do Planalto Médio do Estado do RS (Figura 1).

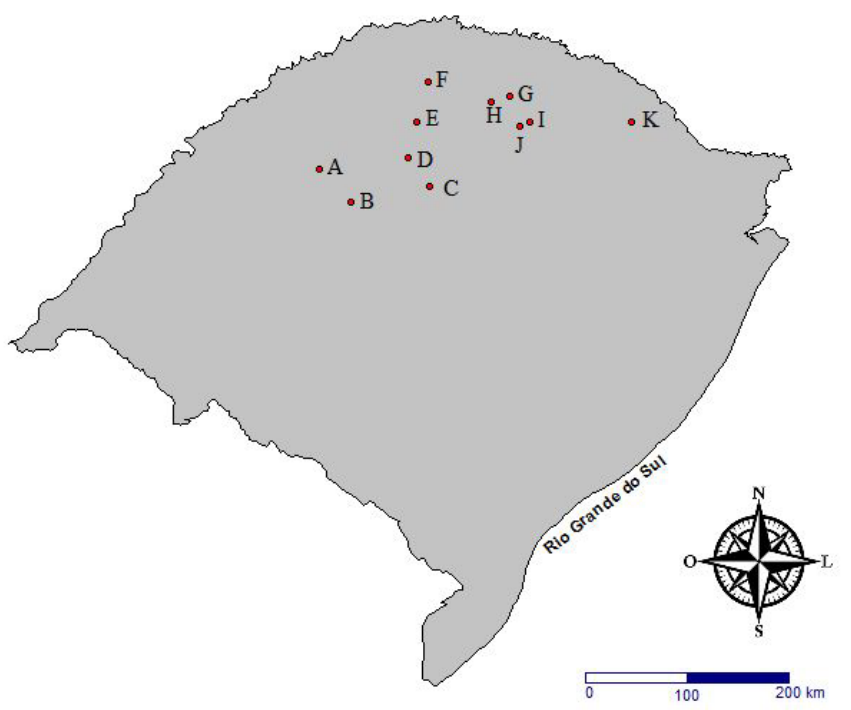

Figura 1 - Localização dos 11 municípios do Planalto Médio do estado do Rio Grande do Sul onde foi realizado o estudo nas 23 áreas de cultivo de milho: (A) São Miguel das Missões; (B) Tupanciretã; (C) Cruz Alta; (D) Pejuçara; (E) Condor; (F) Boa Vista das Missões; (G) Quatro Irmãos; (H) Pontão; (I) Coxilha; (J) Passo Fundo; (K) Capão Bonito do Sul.
Em cada área agrícola foi mensurada a distância longitudinal entre plantas de milho em quatro linhas de semeadura, em estádio vegetativo V3 (terceira folha), conforme semeadora utilizada. Com o uso de fita métrica e de forma aleatória, foram avaliados 10 metros de plantas, em três repetições. A população final de plantas, a qual representa a área ocupada por cada planta $\mathrm{em}^{2}$, foi extrapolada para plantas por hectare, segundo metodologia proposta por Klimionte et al. [9].

Os dados foram tabulados e distribuídos em: espaçamentos aceitáveis, espaçamentos duplos e espaçamentos falhos, conforme metodologia proposta por Kurachi et al. [10] e ABNT [11].

Esta metodologia define, ainda, a porcentagem de espaçamentos aceitáveis $(0,5<\mathrm{XREF} . \leq 1,5)$; duplos $(\leq 0,5$ XREF.); e falhos (> 1,5 XREF.), onde o XREF. é o valor do espaçamento de referência entre uma planta e outra na linha de semeadura, obtido a partir da distância média entre plantas.

De acordo com a classificação sugerida por Tourino \& Klingensteiner [12], é considerado como ótimo desempenho à semeadora que distribuir de 90 a $100 \%$ das sementes na faixa de espaçamentos aceitáveis, bom desempenho de 75 a $90 \%$, regular de 50 a $75 \%$, e insatisfatório abaixo de $50 \%$.

A representação esquemática dos espaçamentos entre plantas de milho na linha de semeadura, em função de três coeficientes de variação, considerando população final de 80.000 plantas por hectare, é apresentada na Figura 2.

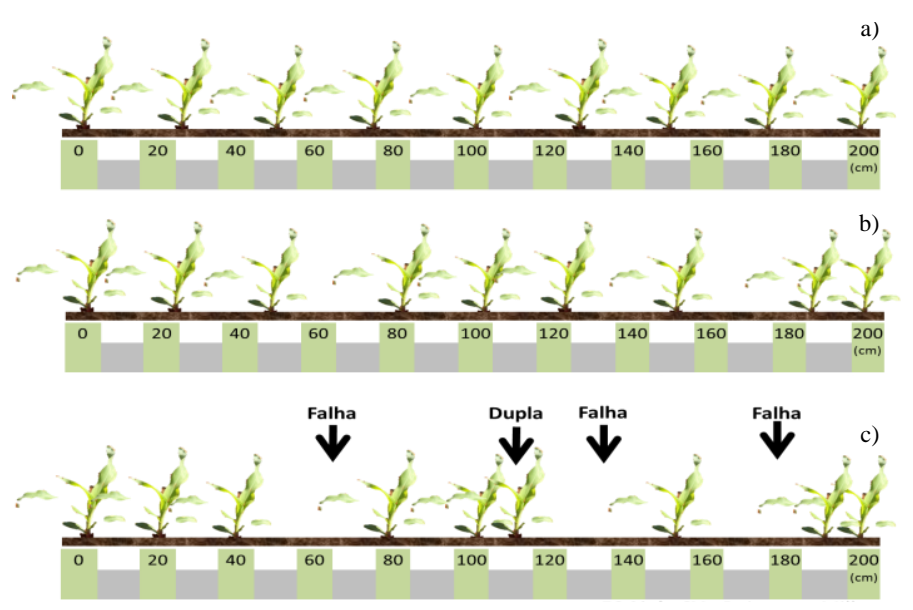

Figura 2 - Espaçamentos entre plantas de milho em função do coeficiente de variação $(\mathrm{CV})$, considerando população final de 80.000 plantas por hectare: a) $\mathrm{CV}$ de $0 \%$; b) CV de $25 \%$; c) CV de $50 \%$. 


\section{REVISTA}

\section{Resultados e discussões}

Os resultados de distribuição longitudinal de plantas de milho na linha de semeadura nos sistemas de cultivo irrigado e sequeiro são apresentados na Tabela 1. Observa-se que, as médias do coeficiente de variação (CV) foram de $38,3 \%$ para o sistema de cultivo irrigado e de $28,9 \%$ para o sistema sequeiro.
O índice de espaçamentos falhos e duplos foi menor nas lavouras conduzidas em sistema de cultivo sequeiro e, consequentemente, o índice de espaçamentos aceitáveis foi maior. As médias de espaçamentos aceitáveis foi diferente para ambos os sistemas, sendo 6,8\% maior para o sistema de cultivo sequeiro $(93,8 \%)$, em comparação ao cultivo irrigado. Na região do Planalto Médio do RS a média geral do CV para todas as áreas estudadas foi de $33,6 \%$.

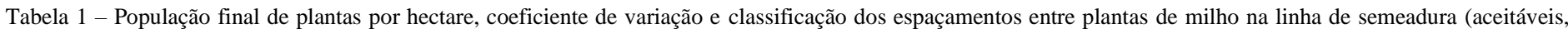
duplos e falhos), no Planalto Médio do Rio Grande do Sul, para os sistemas de cultivo irrigado e sequeiro.

\begin{tabular}{|c|c|c|c|c|c|c|}
\hline Município $^{(1)}$ & N. & Pop. Final ${ }^{(2)}$ & $\mathrm{CV}(\%)$ & Falhos (\%) & Duplos (\%) & Aceitáveis (\%) \\
\hline \multicolumn{7}{|c|}{ Sistema de Cultivo Irrigado } \\
\hline Pejuçara & 1 & 81.600 & 21,0 & 2,3 & 0,7 & 97,0 \\
\hline Pejuçara & 2 & 89.600 & 31,0 & 5,2 & 1,0 & 93,8 \\
\hline Cruz Alta & 3 & 61.000 & 41,0 & 13,5 & 4,5 & 82,0 \\
\hline Cruz Alta & 4 & 71.100 & 36,0 & 11,6 & 1,0 & 87,4 \\
\hline Cruz Alta & 5 & 80.600 & 49,0 & 10,3 & 5,6 & 84,1 \\
\hline Cruz Alta & 6 & 91.500 & 35,0 & 6,4 & 1,1 & 92,5 \\
\hline Cruz Alta & 7 & 83.000 & 79,0 & 20,6 & 23,4 & 56,0 \\
\hline B. V. Missões ${ }^{(3)}$ & 8 & 90.000 & 45,0 & 12,7 & 6,4 & 80,9 \\
\hline B. V. Missões & 9 & 85.800 & 31,0 & 8,8 & 0,9 & 90,3 \\
\hline B. V. Missões & 10 & 90.500 & 39,0 & 6,8 & 4,9 & 88,3 \\
\hline B. V. Missões & 11 & 94.500 & 39,0 & 9,6 & 2,4 & 88,0 \\
\hline B. V. Missões & 12 & 97.600 & 37,0 & 8,9 & 4,9 & 86,2 \\
\hline B. V. Missões & 13 & 81.500 & 27,0 & 3,3 & 1,8 & 94,9 \\
\hline B. V. Missões & 14 & 83.200 & 26,0 & 2,6 & 0,8 & 96,6 \\
\hline Média Irrigado & & 84.393 & 38,3 & 8,8 & 4,2 & 87,0 \\
\hline \multicolumn{7}{|c|}{ Sistema de Cultivo Sequeiro } \\
\hline Condor & 15 & 87.600 & 24,0 & 3,1 & 0,0 & 96,9 \\
\hline Condor & 16 & 79.000 & 23,0 & 0,7 & 3,4 & 95,9 \\
\hline Cruz Alta & 17 & 70.500 & 41,0 & 12,6 & 1,9 & 85,5 \\
\hline Tupanciretã & 18 & 68.000 & 25,0 & 3,0 & 0,0 & 97,0 \\
\hline Passo Fundo & 19 & 83.100 & 30,0 & 5,1 & 2,0 & 92,9 \\
\hline Coxilha & 20 & 80.300 & 26,0 & 2,8 & 0,0 & 97,2 \\
\hline Quatro Irmãos & 21 & 77.000 & 24,0 & 3,2 & 0,0 & 96,8 \\
\hline Pontão & 22 & 77.000 & 34,0 & 6,2 & 4,1 & 89,7 \\
\hline C. B. do Sul ${ }^{(4)}$ & 23 & 76.416 & 33,0 & 5,6 & 2,4 & 92,0 \\
\hline Média Sequeiro & & 77.657 & 28,9 & 4,7 & 1,5 & 93,8 \\
\hline Média Geral & & 81.025 & 33,6 & 6,7 & 2,9 & 90,4 \\
\hline
\end{tabular}

Legenda: (1) Município; (2) População final; (3) Boa Vista das Missões; (4) Capão Bonito do Sul.

De acordo com Portella et al. [13], em solos com maiores teores de umidade ocorrem problemas de embuchamento e aderência de solo aos discos ou hastes sulcadoras. Tal fato pode explicar os menores espaçamentos aceitáveis entre sementes de milho, para a condição de cultivo irrigado. Ainda, o excesso de velocidade de semeadura, independentemente do tipo de sistema dosador de sementes utilizado, afeta negativamente o $\mathrm{CV}$ do espaçamento entre sementes; incidindo diretamente no aumento de plantas falhas e duplas [14].

Com base na classificação proposta por Tourino \& Klingensteiner [12], a distribuição longitudinal de plantas no Planalto Médio do Estado do RS, encontra-se nas faixas de bom e ótimo desempenho para milho em sistema irrigado $(87,0 \%)$ e sequeiro $(93,8 \%)$, respectivamente. Sendo que, de modo geral, $56,5 \%$ das áreas encontravam-se em estado ótimo de desempenho de semeadura, $39,1 \%$ em bom estado de desempenho e $4,4 \%$ em estado regular.

\section{Conclusões}

De modo geral, para a maioria das áreas agrícolas avaliadas, na região do Planalto Médio do Estado do Rio Grande do Sul, é considerada ótima a qualidade na distribuição de plantas de milho na linha de semeadura. 


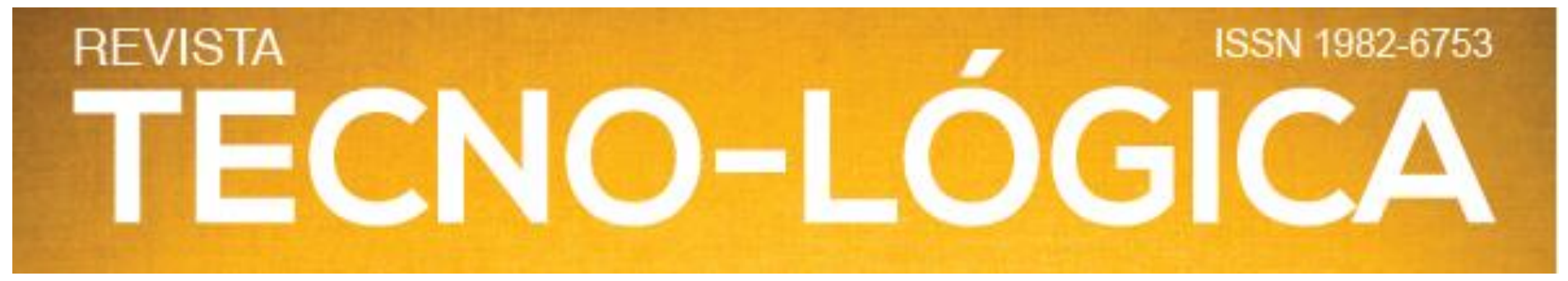

\section{CORN SEEDING QUALITY IN THE MIDDLE PLATEAU OF THE STATE OF RIO GRANDE DO SUL}

ABSTRACT: This paper aimed to determine the quality in the distribution of corn plants in the sowing line, in the Middle Plateau region of the State of Rio Grande do Sul. The study was carried out in the agricultural year 2018/19, in 23 maize cultivation areas, 14 in irrigated system and nine in rainfed system, located in 11 municipalities in the State of Rio Grande do Sul. In each area, the longitudinal distance between corn plants in the sowing line was measured, in the V3 vegetative stage. For that, 10 meters of plants were evaluated, in three repetitions. The data were tabulated and distributed between: acceptable, double and flawed spacing. According to the classification proposed in the classic literature, $56.5 \%$ of the evaluated areas are in an excellent state of distribution of plants in the line, $39.1 \%$ in good condition, and $4.4 \%$ of the areas in regular quality condition of corn sowing. When observing the two cultivation systems, the average of acceptable spacing was $87.0 \%$ for the irrigated system, and $93.8 \%$ for the rainfed one. Thus, it can be concluded that in most of the evaluated areas the quality of the corn sowing crop in the Middle Plateau region is great.

Keywords: Agricultural mechanization. No-tillage System. Plantability.

\section{Referências}

[1] FARIAS, M. S. et al. Desempenho operacional e energético de um trator agrícola durante operação de gradagem. TECNO-LÓGICA, Vol. 22, n. 2, p. 213216, 2018.

[2] DIAS, V. O. et al. Distribuição de sementes de milho e soja em função da velocidade e densidade de semeadura. Ciência Rural, Vol. 39, n. 6, p. 1721-1728, 2009

[3] SANGOI, L. et al. Variabilidade na distribuição espacial de plantas na linha e rendimento de grãos de milho. Revista Brasileira de Milho e Sorgo, Vol. 11, n. 3, p. 268-277, 2012.

[4] CARPES, D. P. et al. Effect of different conductor tubes on the longitudinal distribution of corn seeds. Revista Brasileira de Engenharia Agrícola e Ambiental, Vol. 21, n. 9, p. 657-662, 2017.

[5] MADALÓZ, J. C. C. Distribuição de plantas de milho em sistema pneumático com diferentes regulagens de pressão de vácuo e peneiras de sementes. 2018. $80 \mathrm{f}$. Dissertação (Programa de Pós-Graduação em Agronomia - Mestrado) Universidade Tecnológica Federal do Paraná, Pato Branco. 2018.

[6] HÖRBE, T. A. N. Distribuição espacial de plantas na fileira e sua relação com a produtividade da cultura do milho. 2015. 66 f. (Programa de Pós-Graduação em
Ciência do Solo - Doutorado) - Universidade Federal de Santa Maria, Santa Maria. 2015.

[7] PINHEIRO NETO, R. et al. Desempenho de mecanismos dosadores de sementes em diferentes velocidades e condições de cobertura do solo. Acta Scientiarum Agronomy, Vol. 30, supl., p. 611-617, 2008.

[8] SCHIMANDEIRO, A. et al. Distribuição longitudinal de plantas de milho (Zea mays L.) na região dos Campos Gerais, Paraná. Revista Ciência Rural, Vol. 36, n. 3, p. 977-980, 2006.

[9] KLIMIONTE, M. A. et al. Influência da distribuição de plantas no rendimento de milho (Zea mays L.). In: Congresso Brasileiro de Engenharia Agrícola - SBEA, 30., 2001, Foz do Iguaçu. Anais... Cascavel, PR, Brasil, 2001. 1 CD-ROM.

[10] KURACHI, S. A. H. et al. Avaliação tecnológica de semeadoras e/ou adubadoras: Tratamento de dados de ensaios e regularidade de distribuição longitudinal de sementes. Bragantia, Vol. 48, n. 2, p. 249-262, 1989.

[11] ASSOCIAÇÃO BRASILEIRA DE NORMAS TÉCNICAS - ABNT. Semeadora de precisão - Ensaio de laboratório - Método de ensaio. Rio de Janeiro: ABNT, 1996. 21p. (Projeto de Norma 04:015.06-004/1995).

[12] TOURINO, M. C. C.; KLINGENSTEINER, P. Ensaio e avaliação de semeadoras-adubadoras. In: Congresso Brasileiro de Engenharia Agrícola - SBEA, 13., 1983, Rio de Janeiro. Anais... Seropédica, RJ, Brasil, 1983. p. 103-107.

[13] PORTELLA, J. A. et al. Índice de emergência de plântulas de soja e de milho em semeadura direta no Sul do Brasil. Engenharia Agrícola, Vol. 17, n. 1, p. 7178, 1997.

[14] BOTTEGA, E. L. et al. Qualidade da semeadura do milho em função do sistema dosador de sementes e velocidades de operação. Global Science and Technology, Vol. 7, n. 1, p. 107-114, 2014. 